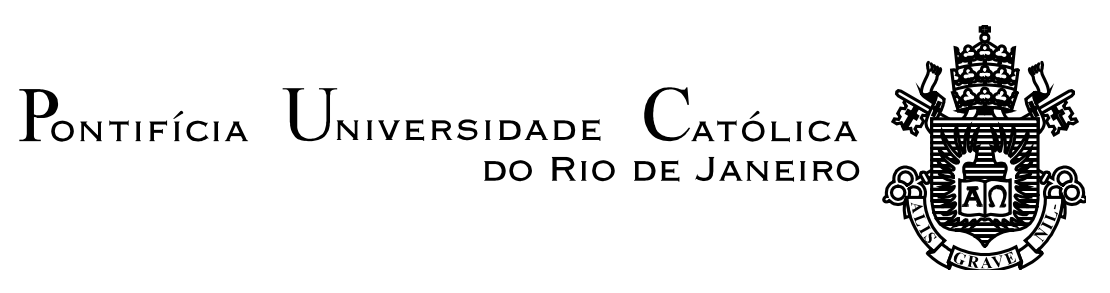

Fernanda Martins Sanromã Marques

\title{
Orações completivas regidas por verbos não factivos: regras de uso e ensino de PL2E
}

\section{Dissertação de Mestrado}

Dissertação apresentada ao Programa de Pós-graduação em Estudos da Linguagem da PUC-Rio como requisito parcial para obtenção do título de Mestre em Letras/Estudos da Linguagem.

Orientadora: Profa. Rosa Marina de Brito Meyer

Co-Orientadora: Profa. Adriana Ferreira de Sousa de Albuquerque

Rio de Janeiro, Agosto de 2013 


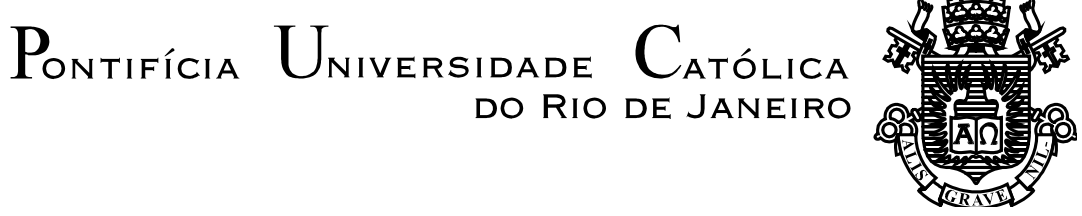

Fernanda Martins Sanromã Marques

\section{Orações completivas regidas por verbos não factivos: regras de uso e ensino de PL2E}

Dissertação apresentada como requisito parcial para obtenção do grau de Mestre pelo Programa de Pós-Graduação em Estudos da Linguagem da PUC-Rio. Aprovada pela Comissão Examinadora abaixo assinada.

Profa. Rosa Marina de Brito Meyer

Orientadora

Departamento de Letras - PUC-Rio

Profa. Adriana Ferreira de Sousa de Albuquerque Co-Orientadora Departamento de Letras - PUC-Rio

Profa. Adriana Leite do Prado Rebello

Departamento de Letras - PUC-Rio

Profa. Danúsia Torres dos Santos UFRJ

Profa. Denise Berruezo Portinari Coordenadora Setorial do Centro de Teologia

e Ciências Humanas - PUC-Rio

Rio de Janeiro, 29 de agosto de 2013. 
Todos os direitos reservados. É proibida a produção total ou parcial do trabalho sem autorização da universidade, da autora e do orientador.

\section{Fernanda Martins Sanromã Marques}

Graduou-se em Letras (Português e Inglês) com habilitação em tradução na PUC-Rio (Pontifícia Universidade Católica do Rio de Janeiro) em 2009.

\section{Ficha Catalográfica}

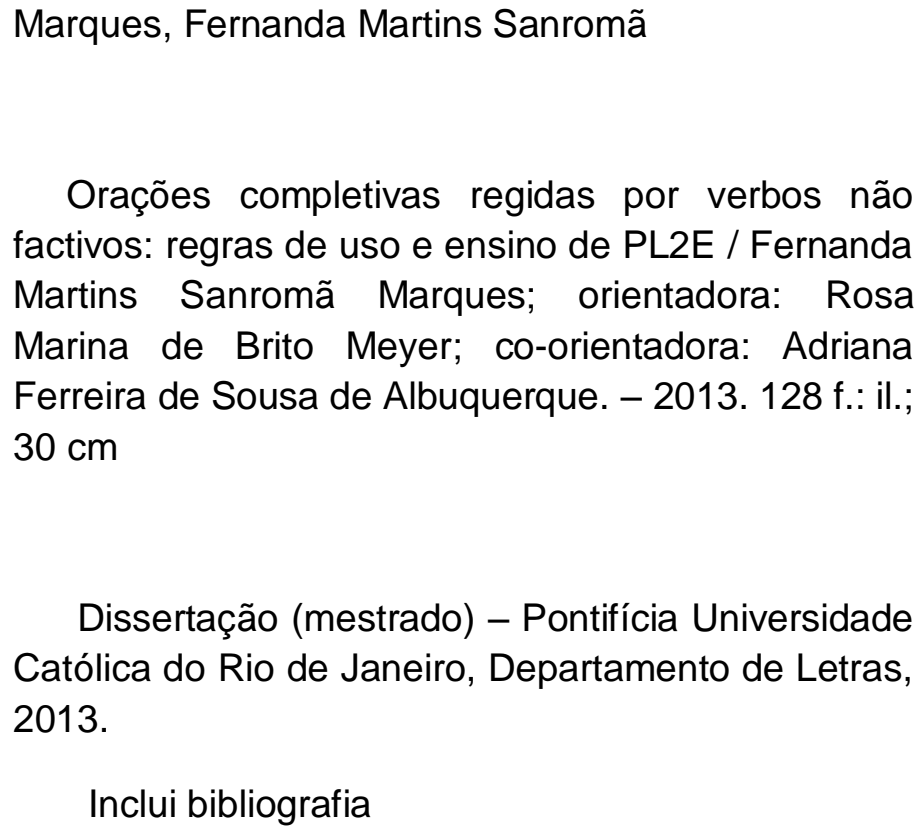
factivos: regras de uso e ensino de PL2E / Fernanda Martins Sanromã Marques; orientadora: Rosa Marina de Brito Meyer; co-orientadora: Adriana Ferreira de Sousa de Albuquerque. - 2013. 128 f.: il.; $30 \mathrm{~cm}$

Dissertação (mestrado) - Pontifícia Universidade Católica do Rio de Janeiro, Departamento de Letras, 2013.

Inclui bibliografia 


\section{Agradecimentos}

À minha orientadora, Professora Rosa Marina de Brito Meyer, pela confiança, pela oportunidade e pelo conhecimento transmitido.

À minha co-orientadora, Professora Adriana Albuqueque, pelas oportunidades oferecidas, pela flexibilidade demonstrada, pelos puxões de orelha e elogios e por todas as tão valiosas sugestões e instruções.

À CAPES e à PUC-Rio, pelos auxílios concedidos, sem os quais este trabalho não poderia ter sido realizado.

Aos meus professores e à PUC-Rio, pela instrução e confiança; bases para este trabalho.

Ao meu namorado, Raffael Capano, que se mostrou não somente compreensivo quando estive ausente estudando e escrevendo, mas também paciente nos momentos de tensão.

Ao meu padrasto, Josè Carlos, por abrir mão das horas de diversão em frente à televisão em prol da minha concentração.

À minha mãe, Carmen Maria, por ser essa pessoa incrível que me faz acreditar na minha capacidade. Seu incentivo, auxílio e carinho foram essenciais. Você é a razão de tudo! 


\section{Resumo}

Marques, Fernanda Martins Sanromã; Meyer, Rosa Marina de Brito. Orações completivas regidas por verbos não factivos: regras de uso e ensino de PL2E. Rio de Janeiro, 2013. 128p. Dissertação de Mestrado Departamento de Letras, Pontifícia Universidade Católica do Rio de Janeiro.

Recentemente têm-se colocado em questão o uso do subjuntivo na Língua Portuguesa falada no Brasil. Fala-se da "morte do subjuntivo", assumindo-se como fato real a hipótese de que as modalidades tradicionalmente expressas por meio do subjuntivo não estão mais sendo expressas por meio deste, ou caminhando para tal fim. O presente estudo busca desmistificar tal assunto analisando o uso de modalidades expressas pelo subjuntivo e pelo infinitivo em orações completivas regidas por verbos não factivos situados nos campos semânticos vontade e pedido/recomendação. Analisam-se, assim, não apenas estruturas em que o subjuntivo e o infinitivo são usados para expressar tais modalidades, tendo-se como critério da escolha de cada modo os sujeitos das orações principais e suas subordinadas, como também estruturas com o uso de Estruturas Alternativas (EAs) para a expressão dessas. Uma vez que tal pesquisa tem como foco a descrição de regras da língua falada, optou-se por realizar tal sistematização de acordo com a Gramática Funcional do Discurso (GDF) e se ter como objeto de estudo o português distenso falado no Brasil, ou seja, o português efetivamente falado pela classe escolarizada brasileira e usado pela mídia. Desta maneira, pode-se contribuir para uma área da descrição da Língua Portuguesa que se encontra, em geral, pouco detalhada e desatualizada em Gramáticas Tradicionais e livros de Língua Portuguesa como Língua Materna e como Segunda Língua.

\section{Palavras-chave}

Subjuntivo; infinitivo; verbos não factivos; orações completivas; ensinoaprendizagem de PL2E. 


\section{Abstract}

Marques, Fernanda Martins Sanromã; Meyer, Rosa Marina de Brito (Advisor). Complement clauses selected by non-factive verbs: rules of use and teaching of P2L. Rio de Janeiro, 2013. 128p. MSc. Dissertation Departamento de Letras, Pontifícia Universidade Católica do Rio de Janeiro.

The use of the subjunctive in spoken Brazilian Portuguese language has been much discussed in the last decades. Much is said about the "death of the subjunctive", assuming as real the hypothesis that modalities traditionally expressed by the subjunctive are no longer being expressed by this mood, or on the way. This study aims to analyze the use of modalities expressed by the subjunctive and the infinitive in complement clauses selected by non-factive verbs of the volitive and request/recommendation semantic areas. Thus, in this dissertation, we analyze not only structures in which the subjunctive and the infinitive are used to express these modalities, considering the main and the subordinate clauses subjects as a criteria for mood choice, but also clauses in which these modalities are expressed with the use of Alternative Structures. Since this research focus on spoken language rules description, we did this systematization according to the Functional Discourse Grammar (FDG) and selected as object of study the Portuguese language Brazilian educated class and media use. That way, this dissertation contributes to an area of the Brazilian Portuguese language description that, in general, needs to be detailed and updated in Traditional Grammars and Portuguese language as native or second language books.

\section{Keywords}

Subjunctive; infinitive; non-factive verbs; complement clauses; teaching and learning of P2L. 


\section{Sumário}

1 introdução 15

1.1 Relevância 17

$\begin{array}{ll}1.2 \text { Hipóteses e objetivos } & 18\end{array}$

$\begin{array}{ll}1.3 \text { Organização do trabalho } & 20\end{array}$

2 Revisão de literatura $\quad 21$

$\begin{array}{ll}\text { 2.1 Livros didáticos de PL2E } & 21\end{array}$

2.1.1 Diálogo Brasil - Curso intensivo de Português 21

para Estrangeiros, 2003

2.1.2 Bem-Vindo - A Língua Portuguesa no Mundo da 24

Comunicação, 2009

2.1.3 Novo Avenida Brasil 3 - Curso Básico de 27

Português para Estrangeiros, 2010

2.1.4 Brasil Intercultural - Língua e cultura 29

brasileira para estrangeiros - nível 2, 2012

2.2 A gramática tradicional 30

2.2.1 Cunha \& Cintra (2001) 30

2.3 Gramáticas de usos $\quad 32$ 
2.3.1 Modern Portuguese - A Reference Grammar (perini, 2002)

2.3.2 Gramática de usos do português (moura neves, 2000)

2.4 Estudos Linguísticos

2.4.1 Estruturas Alternativas (EAS)

2.4.2 Tipologia verbal da oração matriz

3.1 Considerações inicias 38

3.2 A Gramática Funcional do Discurso - GFD 40

3.2.1 Níves de análise da GFD $\quad 40$

3.2.2 A noção de alinhamento na GFD 44

3.3 Pressupostos metodológicos 46

4 Análise $\quad 50$

$\begin{array}{ll}4.1 \text { Análise quantitativa } & 50\end{array}$

4.1.1 A correferencialidade de sujeitos e o uso do 50 subjuntivo 
4.1.3 Sujeito da oração completiva composto e o uso do 53 subjuntivo e do infinitivo

4.1.4 O uso de Estruturas Alternativas

4.2 Análise qualitativa dos dados

4.2.1 Verbos "esperar", "desejar" e "querer"

4.2.1.1 Uso do subjuntivo

4.2.1.1.1 Voz ativa na oração completiva

4.2.1.1.2 Voz passiva na oração completiva

4.2.1.2 Uso do infinitivo

4.2.1.2.1 Voz ativa na oração completiva 
5 Considerações Finais qualitativa

7.1.1 Dados Escritos

7.2 Anexo II - Dados utilizados para a análise quantitativa 
7.2.2 Dados Orais 


\section{Figuras}

Figura 1 - Apresentação do presente do subjuntivo - "Diálogo Brasil - Curso intensivo de Português para Estrangeiros", página 188

Figura 2 - Exercícios - "Diálogo Brasil - Curso intensivo de

Português para Estrangeiros", página 189

Figura 3 - Exercícios - "Diálogo Brasil - Curso intensivo de

Português para Estrangeiros", página 190

Figura 4 - Apresentação do presente do subjuntivo - "Bem-Vindo

- A Língua Portuguesa no Mundo da Comunicação", página 43

Figura 5 - Exercício - "Bem-Vindo - A Língua Portuguesa no

Mundo da Comunicação", página 43

Figura 6 - Exercício - "Bem-Vindo - A Língua Portuguesa no

Mundo da Comunicação", página 44

Figura 7 - Exercício - "Bem-Vindo - A Língua Portuguesa no

Mundo da Comunicação", página 45

Figura 8 - Exercício com casos de sujeitos correferenciais, nota e breve exercício de fixação - "Bem-Vindo - A Língua Portuguesa no Mundo da Comunicação", página 45

Figura 9 - Apresentação do presente do subjuntivo - "Novo Avenida Brasil 3 - Curso Básico de Português para Estrangeiros", 
página 1

Figura 10 - Tabela de regência verbal- "Novo Avenida Brasil 3 Curso Básico de Português para Estrangeiros", página 130

Figura 11 - Apresentação do presente do subjuntivo - "Brasil 29 Intercultural - Língua e cultura brasileira para estrangeiros - Nível 2", página 43 


\section{Tabelas}

Tabela 1 - A correferencialidade de sujeitos e o uso do subjuntivo

Tabela 2 - A correferencialidade de sujeitos e o uso do infinitivo

Tabela 3 - Sujeito da oração completiva composto incluindo o sujeito da oração principal

TABELA 4 - O uso de Estruturas Alternativas

Tabela 5 - Estruturas com sujeitos não-correferenciais e o uso do subjuntivo

Tabela 6 - Estruturas com sujeitos correferenciais e o uso do subjuntivo o uso do infinitivo

Tabela 7 - Estruturas Alternativas do uso do subjuntivo

Tabela 8 - Estruturas Alternativas do uso do infinitivo 